\title{
Introduction to Special Issue on Advances and Applications of Surface Analysis Methods
}

\author{
Donald R. Baer
}

Pacific Northwest National Laboratory, P. O. Box 999 MSIN K8-91 Richland WA 99352

don.baer@pnnl.gov

Abstract: Introduction to the special issue on surface analysis, providing thumbnail sketches of several popular techniques. A table gives the capabilities of each technique.

\section{Introduction}

Surfaces and interfaces of many types play a critical role in modern technologies associated with electronics, chemical and petroleum processing, energy conversion and storage, as well as medicine and health. The role of surfaces and interfaces in various forms is important to natural and engineered nanotechnologies of all types because interfaces between materials and biological systems impact medical technology, environmental quality, the formation of aerosols, carbon and nitrogen cycling, and climate change. As the features being analyzed decrease in size, the distinction between bulk analysis of small objects and surface analysis disappears, and any tool that can provide compositional (or structural) information on the desired spatial scale will be useful.

Rather than focus this special issue only on surface analysis tools (which was well done by Vince Smentkowski and colleagues in the March 2011 issue of Microscopy Today), we have chosen to provide examples of how surface analysis tools, in combination with a variety of other analysis tools, are being used to address analysis challenges important in several areas of technology and science. An article on batteries will highlight a variety of techniques being used to address issues associated with the development of improved components for $\mathrm{Li}$ ion batteries and more advanced battery systems. Because of the health and environmental importance of biological systems, one article highlights secondary ion mass spectrometry (SIMS) imaging of tissues, cells, and microbial systems demonstrating the ability of SIMS to collect useful information from features of widely different sizes. As shown in the article by Cedric Powell, the use of X-ray photoelectron spectroscopy (XPS) has continued to grow faster than other surface analysis methods. In part this growth has been aided by the development of databases and software that enable analyses to be increasingly quantitative and easy to perform. The use of XPS and modeling software to quantitatively determine the thickness of coatings on nanoparticles demonstrates the added value that modeling brings to XPS analysis and how information obtained by XPS can complement that collected by microscopy methods.

Schematic drawings of some surface- and interface-sensitive methods are shown in Figure 1. The 2011 special issue on surface-analysis tools included discussions of Auger electron spectroscopy (AES), X-ray photoelectron spectroscopy (XPS),

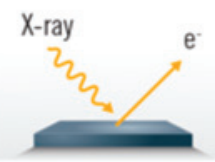
spectroscopy time-of-flight secondary ion mass spectrometry (ToF-SIMS), and low-energy ion scattering (LEIS, also identified as ion scattering spectroscopy, ISS). These methods are sensitive to the outer few nanometers of a material, except for LEIS/ ISS, which is sensitive to the topmost layer. Other less traditional interfacially sensitive tools mentioned in this issue include atom probe tomography (APT), mediumenergy ion scattering (MEIS), and high-spatial-resolution SIMS (NanoSIMS). In many cases these methods can be correlated or directly tied to core microscopy methods including various forms of TEM and SEM. Short summary overviews of these methods are included below and in Figure 1 and Table 1 as a reminder of their nature, recent advances, and limitations.

The relative use of a variety of analysis tools based on a Web of Science topical search for 2014 through October 2015 is shown in Figure 2. Of the surface-analysis methods, XPS is the most widely used tool as will be described in more detail in the article by Powell. SIMS, LEIS, and AES are used much less often for a variety of reasons, some of which will be noted below. Transmission electron microscopy (TEM), scanning electron microscopy (SEM), nuclear magnetic resonance (NMR), and scanning probe methods (including AFM) are all important materials analysis methods with SEM being the most widely used method on this list. The graph shows that the use of NMR and TEM is about a factor of two greater than XPS, while the reported use of other surface analysis methods is significantly less.

X-ray photoelectron spectroscopy (XPS) is widely used for a number of reasons, as discussed in the Powell article in this issue. That article shows the development of a variety of support information and established procedures and standards that enable XPS to be surface-sensitive, quantitative, and reproducible. AES and SIMS have not reached the
X-ray photoelectron

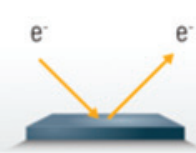

Auger electron spectroscopy
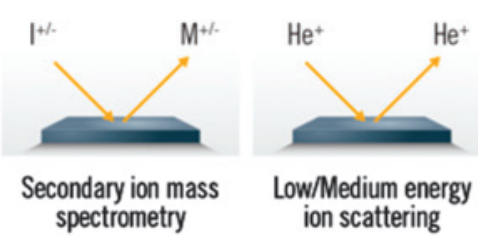

Figure 1: Schematic representations of six important surface and interface analysis tools. XPS, AES, and SIMS are the most commonly used tools. LEIS is an update of an old method for which new instrumentation provides enhanced signal strength and additional information. Technologies advances have improved the spatial resolution of MEIS and are making APT valuable for obtaining interfacial information on an atomic scale for many types of materials systems. 
Table 1: General characteristics of a selection of surface and interface analysis methods.

\begin{tabular}{|c|c|c|c|c|c|c|}
\hline Technique & Information Available & Probe & Detected & $\begin{array}{c}\text { Lateral } \\
\text { Resolution }\end{array}$ & $\begin{array}{l}\text { Information } \\
\text { Depth }^{*}\end{array}$ & $\begin{array}{c}\text { Depth } \\
\text { Resolution }\end{array}$ \\
\hline $\begin{array}{c}\text { X-ray } \\
\text { Photoelectron } \\
\text { Spectroscopy } \\
\text { (XPS) }\end{array}$ & $\begin{array}{l}\text { - Analysis of a surface or a collection of } \\
\text { particles deposited on a substrate } \\
\text { - Ion sputtering to obtain additional } \\
\text { depth information } \\
\text { - Surface composition and/or chemical } \\
\text { state } \\
\text { - Enrichment or depletion of elements } \\
\text { at surface } \\
\text { - Presence and/or thickness of } \\
\text { coatings or contaminats }\end{array}$ & $\begin{array}{l}\text { X-rays } \approx 1-2 \mathrm{keV} \\
\text { for lab-based } \\
\text { systems }(\mathrm{e} . \mathrm{g} . \\
\mathrm{Mg} \mathrm{K} \alpha, \mathrm{Al} \mathrm{K} \alpha)\end{array}$ & $\begin{array}{l}\text { Photo } \\
\text { and Auger } \\
\text { electrons }\end{array}$ & $\begin{array}{l}\sim 2 \mu \mathrm{m} \text { mapping } \\
\sim 10 \mu \mathrm{m} \text { small } \\
\text { area System- } \\
\text { dependent } \\
\text { System- } \\
\text { dependent }\end{array}$ & $\begin{array}{l}2-10 \mathrm{~nm} \\
\sim 3 \times(\text { effective } \\
\text { electron } \\
\text { attenuation } \\
\text { length) }\end{array}$ & $\sim 2 \mathrm{~nm}$ \\
\hline $\begin{array}{l}\text { Auger } \\
\text { Electron } \\
\text { Spectroscopy } \\
\text { (AES) }\end{array}$ & $\begin{array}{l}\text { - Surface composition of material or } \\
\text { individual large nanoparticles } \\
\text { - Enrichment or depletion of elements } \\
\text { at surface } \\
\text { - Ion sputtering to obtain additional } \\
\text { depth information } \\
\text { - Presence and/or thickness of } \\
\text { coatings and/or contaminants }\end{array}$ & $\begin{array}{l}\text { Electrons } \\
3-20 \mathrm{keV}\end{array}$ & $\begin{array}{l}\text { Auger } \\
\text { electrons }\end{array}$ & $\sim 10 \mathrm{~nm}$ & $2-10 \mathrm{~nm}$ & $\sim 2 \mathrm{~nm}$ \\
\hline \multirow{3}{*}{$\begin{array}{l}\text { Secondary } \\
\text { Ion Mass } \\
\text { Spectrometry } \\
\text { (SIMS) } \\
\text { Instrumentation, } \\
\text { ion source, } \\
\text { and use mode } \\
\text { depend on the } \\
\text { information } \\
\text { needed. }\end{array}$} & $\begin{array}{l}\text { - Surface elemental, molecular, and } \\
\text { isotopic composition (Static Mode). } \\
\text { Many instruments allow surface } \\
\text { imaging or 2D mapping. }\end{array}$ & Ions $15-60 \mathrm{keV}$ & $\begin{array}{l}\text { Sputtered } \\
\text { ions }\end{array}$ & $\begin{array}{l}\text { lon- and } \\
\text { instrument- } \\
\text { dependent } \\
80 \mathrm{~nm}-10 \mu \mathrm{m}\end{array}$ & $\begin{array}{l}\text { Less than } 1 \mathrm{~nm} \\
\text { (inorganic); } \\
\text { less than } 3 \mathrm{~nm} \\
\quad \text { (organic) }\end{array}$ & $\begin{array}{l}\text { Less } \\
\text { than } 1 \mathrm{~nm} \\
\text { possible }\end{array}$ \\
\hline & $\begin{array}{l}\text { - Subsurface elemental, molecular, } \\
\text { and isotopic composition (Dynamic } \\
\text { Mode). Continuous or pulsed ion } \\
\text { beam sputtering used to provide } \\
\text { depth profiles and/or 3D maps. }\end{array}$ & Ions $0.2-60 \mathrm{keV}$ & $\begin{array}{l}\text { Sputtered } \\
\text { ions }\end{array}$ & $\begin{array}{l}\text { lon- and } \\
\text { instrument- } \\
\text { dependent } \\
50 \mathrm{~nm}->50 \mu \mathrm{m}\end{array}$ & $\begin{array}{l}\text { Instrument, } \\
\text { operation } \\
\text { mode, and ion } \\
\text { dependent } \\
\text { from less than } \\
1 \mathrm{~nm}-\sim 10 \mathrm{~nm}\end{array}$ & $\begin{array}{l}\text { Less } \\
\text { than } 1 \mathrm{~nm} \\
\text { (inorganic); } \\
\text { less than } \\
5 \mathrm{~nm} \\
\text { (organic) }\end{array}$ \\
\hline & $\begin{array}{l}\text { - High precision (isotopic) composition, } \\
\text { often utilized for geological } \\
\text { application and forensic analysis, } \\
\text { such as stable light isotope analysis, } \\
\text { age determination for rocks, and } \\
\text { source determination for atomic } \\
\text { weapon materials }\end{array}$ & Ions $5-25 \mathrm{keV}$ & $\begin{array}{l}\text { Sputtered } \\
\text { ions }\end{array}$ & $5 \mu \mathrm{m}-30 \mu \mathrm{m}$ & $\begin{array}{c}\text { Precision need } \\
\text { dependent } \\
1-3 \mu \mathrm{m}\end{array}$ & $\begin{array}{l}\text { Dependent } \\
\text { on matrix } \\
\text { and required } \\
\text { precision, } \\
\text { typically } \\
1 \mu \mathrm{m}\end{array}$ \\
\hline $\begin{array}{l}\text { Ion Scattering } \\
\text { Low-energy and } \\
\text { medium energy }\end{array}$ & $\begin{array}{l}\text { - Low-energy ion scattering (LEIS): } \\
\text { Presence of ultra-thin coatings or } \\
\text { contamination, defects in surface } \\
\text { coverage, average particle size }\end{array}$ & Ions $\sim 2-10 \mathrm{keV}$ & $\begin{array}{l}\text { Elastically } \\
\text { scattered } \\
\text { ions }\end{array}$ & $\begin{array}{l}\sim 50 \mu \mathrm{m}(\sim 5 \mu \mathrm{m} \\
\text { with high } \\
\text { brightness } \\
\text { source })\end{array}$ & $\begin{array}{l}0.1 \mathrm{~nm} \text { typical } \\
\sim 10 \mathrm{~nm} \\
\text { possible }\end{array}$ & $\sim 0.1 \mathrm{~nm}$ \\
\hline $\begin{array}{l}\text { are useful for } \\
\text { characterization } \\
\text { of surfaces and } \\
\text { nanoparticles. }\end{array}$ & $\begin{array}{l}\text { - Medium-energy ion scattering } \\
\text { (MEIS): Elemental depth distribution } \\
\text { in particles and coatings, layer } \\
\text { thickness, crystal quality and defect } \\
\text { location, surface structures }\end{array}$ & Ions $50-200 \mathrm{keV}$ & $\begin{array}{l}\text { Elastically } \\
\text { scattered } \\
\text { ions }\end{array}$ & $10 \mu \mathrm{m}$ (TOF) & $\sim 50 \mathrm{~nm}$ & $\sim 0.2 \mathrm{~nm}$ \\
\hline $\begin{array}{l}\text { Atom Probe } \\
\text { Tomography } \\
\text { (APT) }\end{array}$ & $\begin{array}{l}\text { - Spatially resolved isotopic mapping } \\
\text { of all elements in periodic table in } \\
\text { materials } \\
\text { - 3D quantitaive compositional analysis } \\
\text { of surfaces, grain boundaries, and } \\
\text { burried interfaces using repeated } \\
\text { pulses } \\
\text { - Analysis of spatially resolved } \\
\text { composition of nano-objects }\end{array}$ & $\begin{array}{l}0.5-20 \mathrm{keV} \\
\text { standing voltage } \\
+ \text { voltage or } \\
\text { laser pulse }\end{array}$ & $\begin{array}{l}\text { Evaporated } \\
\text { ions }\end{array}$ & $0.3 \mathrm{~nm}$ & $0.2 \mathrm{~nm}$ & $0.2 \mathrm{~nm}$ \\
\hline
\end{tabular}

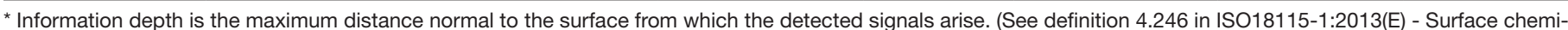
cal analysis - Vocabulary - Part 1, General terms and terms used in spectroscopy). Supplementary methods such as sputter depth profiling allow information to be obtained deeper in a material to construct depth profiles or 3D images. 
use rate for XPS for several reasons, which are different for each method.

Auger electron spectroscopy (AES) has useful spatial resolution that is important for many materials applications but suffers from a high background signal. Sample charging limits analysis of highly insulating materials, although excellent progress has been made in minimizing these difficulties [1]. Also, the electron beam readily damages organic layers or coatings.

Secondary ion mass spectroscopy (SIMS) has benefited from a variety of recent technical developments. SIMS can be implemented with different types of mass spectrometers (including: time of flight, magnetic sector, Fourier transform ion cyclotron resonance, and quadrupole) and use a variety of ion sources having a range of beam sizes and other properties. As discussed by Gamble and Anderton in the SIMS imaging paper in this issue, each type of instrumentation has advantages and limitations. Increasingly the instruments can have multiple modes of operation, which we have tried to capture in Table 1. Polyatomic ion sources have made it possible to apply SIMS (in 2 and 3 dimensions) to organic and biological materials to obtain information that was not previously available. Because of differences in ionization fractions and molecular fragmentation, data can be difficult to quantify. However, it has high sensitivity and the ability to sense isotopic differences. The many new developments in SIMS technologies are leading to new applications.

Low- and medium-energy ion scattering (LEIS and MEIS) are not widely used but can provide important information. The current advanced form of LEIS with improved sensitivity and resolution [2] has an important role to play as the most "surface-sensitive" of the surface analytical tools [3]. It provides important information about the composition of the very outer atomic layer of surfaces, flat or in particle form. Using the improved sensitivity along with careful analysis, LEIS can also be used to obtain depth and coating thickness information [2]. Such LEIS measurements have been used to extract the thickness of self-assembled monolayers on Au nanoparticles [4] in comparison to XPS results as noted in the nanoparticle coating paper by Baer et al. in this issue. The somewhat more energetic form of ion scattering (MEIS) has both a traditional form based on electrostatic analyzers (ESA) and a recent form based on time-of-flight (TOF) analysis[5]. It can provide important information about layered structures, including the layer structure of nanoparticles $[6,7]$.

Atom probe tomography (APT) may be considered the new kid on the block (although it has a strong historical pedigree). It can provide three-dimensional, quantitative information about the distribution of atoms (of any mass) at atomic resolution within needle-shaped samples [8]. It has played an important role in the battery work discussed in the paper by Wang et al. in this issue. One

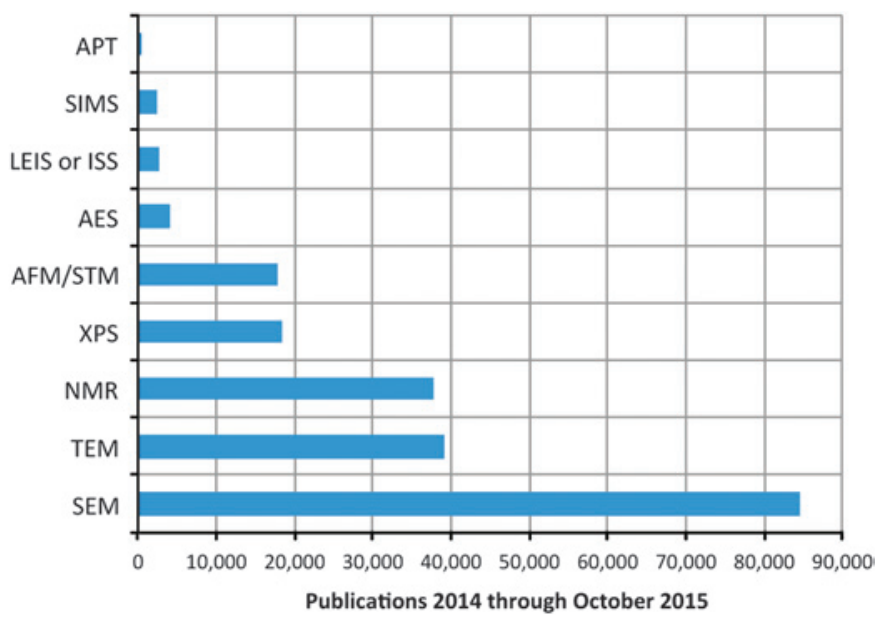

Figure 2: Comparison of the number of publications during 2014 and the first eight months of 2015 associated with surface analysis, microscopy, and other analytical methods. XPS is the most widely used surface analysis method at about half the rate of TEM and NMR.

of the challenges of APT is the preparation of the sharp needle sample such that the analyst can obtain the desired information from an appropriate region of a bulk sample. Focused ion beam (FIB) milling is now used to produce needle samples of the appropriate dimensions from almost any material of interest [9]. Traditionally, APT analysis was relegated mainly to electrically conductive systems; however FIB sample preparation and the introduction of lasers and local electrode geometries of modern atom probes have opened up application to many other areas of materials science [10].

Advances in understanding of these methods mean that the information in Table 1 is subject to continuous improvement. Developments associated with LEIS, SIMS, and MEIS have been noted above. Important advances in XPS related to higher-than-normal pressures [11] and capabilities enabled by high-energy $\mathrm{X}$ rays [12] are not included in Table 1 . In addition to the SIMS advances already mentioned, the new ability to examine liquid surfaces and the solid/liquid interface provides new ways to examine biological systems [13] and solid/liquid systems such as batteries [14] (as described in the article by Wang et al. in this issue). While these surface analysis methods continually improve over time, it is often their complementary nature and integration with information obtained from other methods that is important in solving problems. More detailed information about each method can be obtained from a variety of sources [15-19].

Improvements in terminology also help our understanding of surface analysis. Terms have been carefully defined by ISO Committee 201 Surface Chemical Analysis (including information depth and depth resolution as used in Table 1 are now available at no charge through a variety of websites that can be found in ref [20].) Concepts underlying terminology can have important implications. For example, although the 
effective attenuation length of electrons $(\lambda)$ in XPS is typically 1 to $3 \mathrm{~nm}$, the depth from which $95 \%$ of the signal arises is $\approx 3 \lambda$ or up to $\approx 10 \mathrm{~nm}[21]$. Thus the information depth is larger than $\lambda$, although $\lambda$ has been often been identified as the sampling depth.

I want to thank each of the authors who contributed to the articles in this issue. These brief summaries demonstrate the advanced uses of surface analysis and usually in combination with microscopy and other methods to address problems of importance to all of us.

\section{References}

[1] DR Baer et al., J Electron Spectrosc 176 (2010) 80-94.

[2] HH Brongersma et al., Vacuum 84 (2010) 1005-07.

[3] HH Brongersma et al., Surf Sci Rep 62 (2007) 63-109.

[4] A Rafati et al., "Low Energy Ion Scattering: Determining Overlayer Thickness for Functionalized Gold Nanoparticles," Surf Interface Anal (2013) (in press).

[5] K-W Jung et al., Anal Chem 86 (2014) 1091-97.

[6] PL Grande, Recent advances of MEIS for near surface analysis (2011): www. slideshare.net/Engenharia.de.Superficies/ recent-advances-of-meis-for-near-surface-analysis.

[7] J Gustafson et al., Surf Sci 605 (2011) 220-24.

[8] MK Miller et al., Materials Today 15 (2012) 158-65.

[9] K Thompson et al., Ultramicroscopy 107 (2007) 131-39.

[10] EA Marquis et al., Curr Opin Solid St M 17 (2013) 217-23.
[11] M Salmeron and R Schlögl, Surf Sci Rep 63 (2008) 169-99.

[12] M Taguchi et al., J Electron Spectrosc 190 Part B (2013) $242-48$.

[13] X Hua et al., Analyst 139 (2014) 1609-13.

[14] Z Zhu et al., Nano Lett 15 (2015) 6170-76.

[15] DR Baer et al., "Characterization of Thin Films and Coatings, 3rd Edition," in Handbook of Deposition Technologies for Films and Coatings, P. M. Martin ed., William Andrew Press, New York, 2009.

[16] CR Brundle et al., Encyclopedia of Materials Characterization: Surfaces, Interfaces, Thin Films, Butterworth-Heinemann, Greenwich, CT, 1992.

[17] DR Baer et al., J Vac Sci Technol A 31 (2013) 050820.

[18] JC Rivière and S Myhra, Handbook of surface and interface analysis: methods for problem-solving: CRC Press, Boca Raton, FL, 2009.

[19] MK Miller and RG Forbes, Atom-Probe Tomography: The Local Electrode Atom Probe, Springer, New York, 2014.

[20] CJ Powell et al., Surf Interface Anal 47 (2015) 127-34.

[21] D Briggs, “XPS: Basic Principles, Spectral Feaatures and Qualitative Analysis," in Surface Analysis by Auger and $X$-ray Photoelectron Spectroscopy D Briggs, JT Grant eds. IM Publications and Surface Spectra Limited, Chichester, West Sussex, UK, 2003) 31-56.

\section{uSight"

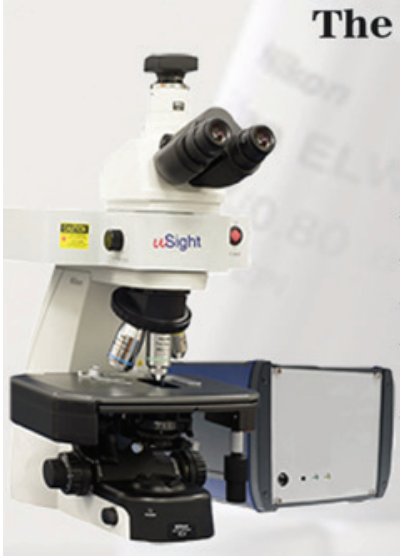

uSight-X-785nm with external detector mounted on Nikon Ci-L Microscope

\section{uSight - X}

* Laser spot size down to <1.0 um

* User controllable laser power

* Polarization add on option

* Available in $532 \mathrm{~nm}, 633 \mathrm{~nm}, 785 \mathrm{~nm}$ excitation wavelength

* Suitable for Raman, Photoluminescence and Fluorescence

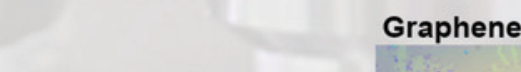

Spectrum from uSight - $X$

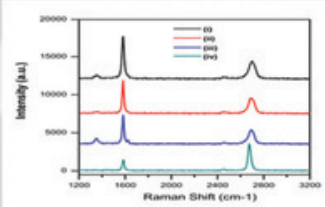

\section{uSight - 2000}

* Small footprint

- Motorized XY stage control

* Measurement spot $<1.0$ um

* Suitable for Reflectance, Absorbance and Transmittance measurement

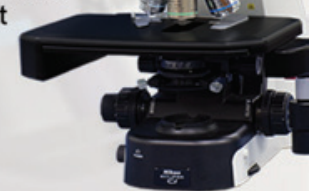

uSight-2000 mounted on Nikon Ci-L Microscope

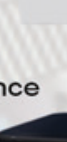

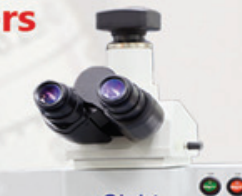

usight

B (2013) 